\title{
Study on Planning and Design of Rainwater System Based on the Concept of Sponge City
}

\author{
Hongli Huang ${ }^{1}$, Liangsong $\mathrm{Li}^{2}$ \\ ${ }^{1}$ Jiangxi University Of Engineering, Xinyu, Jiangxi, 338000, China \\ ${ }^{2}$ Pingxiang University, Pingxiang, Jiangxi, 337000, China
}

\begin{abstract}
In recent years, the concept of sponge city has been applied in different places. There are also many experts on sponge cities who believe that to build a sponge city in the city, we need to improve and optimize the rainwater system. In this way, we can better explore the way to plan and design the stormwater system when conducting the construction of the sponge city. This paper will also analyze and study the characteristics and functions of rainwater system planning in the construction of sponge city, and also point out the difficulties of the city in the construction of sponge city. Nowadays, the city must make clear its optimization direction, methods and principles in the transformation of rainwater system, and the optimization and transformation of rainwater system can also improve the construction progress of sponge city faster. The optimization and application of rainwater system can lay a solid foundation for the construction of sponge city.
\end{abstract}

\section{Introduction}

With the rapid development of Chinese urbanization, the drainage pressure of rainwater pipes in previous cities is also gradually increasing. In addition, the original drainage system has been aging, which can no longer play the role of relieving rain drainage, which makes waterlogging often occur in cities. The original intention of building a sponge city is to reduce the frequency of waterlogging in the city and to promote the development of the city. The state 's urban construction department started early on the planning to create a sponge city, and made many requirements and suggestions on the city' $\mathrm{s}$ rainwater system. Therefore, this paper will plan and optimize the rainwater system according to the way of creating a sponge city.

\section{Proposal of Rainwater System Planning of Sponge City Concept}

China's economy is developing, and urban scale construction is expanding with the economic development, which also makes the way of land use changing. According to expert research, China 's urbanization will account for more than half of the country' $\mathrm{s}$ land, and the continuous expansion of urbanization will also make many green ecological land occupied by urban land. Once a large number of green, ecological land such as fields, green space and wetlands is occupied and covered by the reinforced concrete of urban land, it is difficult for rainwater to smoothly penetrate into the land, and it will easily cause urban waterlogging. The contradiction between urbanization and ecological land is also getting bigger and bigger because of the mutual coexistence, and the rain and waterlogging problems closely related to urban development and progress are becoming more and more difficult to solve and complex. On the one hand, urban waterlogging caused by heavy rain is becoming more and more prominent. China collected flood control in cities in 13 years, and the results showed that more than 340 other cities did not meet the standards now issued by the state. Of them, only seven of the dozens of cities with a population of more than 1. 5 million yuan have reached the flood control standards set by the state. And the National Flood Control Headquarters has counted that more than 100 cities suffered waterlogging in 14 years. In 2016, due to the El Nile phenomenon, many cities in China were affected by waterlogging. In particular, Wuhan has been very severe waterlogging because of the continuous rainstorm city, the traffic in the city is paralyzed, the water in some places is even 1 meter deep. Such serious waterlogging has also caused great inconvenience to their life, work and travel in Wuhan[1]. On the other hand, China 's freshwater resources account for 6 percent of the world ranked fourth in the world, but because China' s population is mostly, $6 \%$ of the world's total water resources are evenly shared to every Chinese. So according to population, China is one of the 13 countries with the most scarce freshwater resources in the world. There are still many cities in China that still use the previous drainage methods, but simply collect the rainwater and then discharge it. The urban prevention of waterlogging 
is only simply "drainage". It is precisely because of this simple drainage method that nearly $90 \%$ of the urban drainage can only rely on drainage pipes. This also increases the pressure of urban drainage pipes, and this "drainage" way makes many water resources cannot be effectively used. Therefore, it requires urban managers to find effective ways to reduce urban waterlogging, and to improve the utilization rate of water resources while alleviating urban waterlogging disasters.

The rainwater system in the city is the most important infrastructure in the city creation, which has an important task of flood discharge and is also an important index to evaluate whether the city can develop healthily. In the early stage of the urbanization process, waterlogging prevention is carried out through drainage pipes, but with the rapid development of economy and society, urbanization is also getting faster and faster. Because of the development of urbanization, there is more and more reinforced concrete ground in the city, the road is more and more hardened. While hardening of the road also makes the runoff on the ground bigger and bigger, so the original drainage pipes cannot be effectively drained in case of particularly heavy rain. China has been looking for new drainage methods to reduce the burden of drainage pipes, hoping that the new drainage methods can not only reduce the impact of waterlogging on cities, but also better protect the ecological environment. It is under the influence of these two goals that China decided to refer to the advanced successful experience of waterlogging prevention in western and other countries - - to build a sponge city[2].

\section{Study of Rainwater System in Sponge City at home and abroad}

\subsection{Current research status of sponge cities abroad}

The theory of sponge city has not been proposed for a long time, but it is actually very similar to the methods of water control in ancient Chinese times and the other more popular methods of waterlogging prevention in the world. Around the $1970 \mathrm{~s}$ and $1980 \mathrm{~s}$, the United States already had a way to prevent a large amount of drainage, which mainly relies on ponds and wetlands to reduce pollution from runoff. But this way is very much and the drainage is very slow, there are very serious shortcomings. After the 1990 s, the US Environmental Protection Agency developed better waterlogging prevention technology, which, although more advanced than previous rain systems, was still uncontrollable in the face of heavy rain. Within a few years, the American Resource Conservancy has studied floods more carefully on how to minimize the impact on the environment. After a few years, this very small drainage method with environmental impact has been studied, which can be used for the reconstruction of old cities and the ecological environment. In 2007, US authorities pointed out that to get cities out of rain and waterlogging, they need to learn to use this drainage method with little environmental impact. After the use of this drainage method, the United States can well discharge rainwater runoff at the source and tail of rainwater, and this drainage method is basically the same as the concept of sponge cities in China. In the $1990 \mathrm{~s}$, the UK formed a sustainable drainage system with the help of BMPs. This sustainable drainage system can well control the rainwater discharge and is very easy to manage and maintain. Similar sustainable drainage systems (now also known as water - sensitive drainage systems) were developed in Australia during this same period. This water - sensitive drainage system is the overall planning of the drainage system mainly on and through the amount of rainwater, the quality of the water, the water scene and the ecological environment of the water. However, the water - sensitive drainage system can make the urban water circulation more sustainable, which has much help to the development of the city. Many developed countries have also used this concept. For example, Germany has made full use of the water resources in the rainstorm, a water - sensitive network system that can collect and store filtered rainwater, and Germany has put the water resources through this characteristic into the market. The waterlogging prevention method adopted by these countries also provides some experience in building a sponge city in China[3].

\subsection{Current status of sponge city}

China has a history of more than 5, 000 years. In ancient times, we left many material civilizations for us, and there are many waterlogging prevention cases in the material civilization that can provide reference for China to build a sponge city. For example, in the Northern Song Dynasty, a drainage project named Fushougou " was built. The project was divided into two ditches with a total length of 12.6 kilometers. Fugou is used to drain the water in the southeast city, while Shoushan is used to drain the water from the southwest city. The Fushou two ditches use a combination of open canals and culverts to connect with the ponds outside the city to drain the water produced by the heavy rain, and can also drain the water to cultivate aquatic plants. Thousands of years later, today there are still more than 900 meters of sewer is still playing a huge role, which should be the earliest sponge city in the history of the world. However, it is a pity that China's flood prevention methods in recent decades have relied on rainwater pipeline systems to solve them and invested very little into the rainwater flood prevention system. Therefore, the drainage systems in most Chinese cities have not developed very much. In the $1980 \mathrm{~s}$, China has carried out the corresponding systematic theoretical research and practice on the flood prevention system. Nowadays, many researchers are also in China are very interested in the construction of waterlogging prevention systems. For example, Chen Liwen from Taiwan put forward the waterlogging prevention method of sponge body based on the experience of ancient and modern Chinese and foreign drainage systems. At the same time, Che and others proposed to promote the drainage system with "drainage, 
storage, net" and other characteristics. Zhou Yuwen and others have also provided solutions to the urban waterlogging disasters. These theories have the use of waterlogging prevention experience in other western countries and the use of flood prevention knowledge in ancient times[4].

\section{Main measures for Sponge city construction}

From the following table, the greater the control rate of the total annual runoff, the greater the reduced runoff peak rate. Moreover, when the control rate of the total runoff amount reaches a certain extent, the weakening effect of the peak precipitation runoff peak within a certain time will be a better one.

\begin{tabular}{|c|c|c|c|c|c|c|c|c|c|c|}
\hline \multirow{2}{*}{$\begin{array}{l}\text { Annual total } \\
\text { runoff volume } \\
\text { control rate }\end{array}$} & \multicolumn{2}{|c|}{$\begin{array}{l}\text { rainfall } \\
\text { reappearing }\end{array}$} & \multicolumn{8}{|c|}{ Rainfall duration (min) } \\
\hline & & & 10 & 15 & 20 & 30 & 45 & 60 & 90 & 120 \\
\hline \multirow{3}{*}{$60 \%$} & 2 & 100.0 & 78.2 & 60.5 & 43.4 & 33.0 & 28.8 & 27.4 & 26.8 & 26.5 \\
\hline & 3 & 99.0 & 66.5 & 50.6 & 35.3 & 26.1 & 25.4 & 24.6 & 24.8 & 23.2 \\
\hline & 5 & 84.7 & 56.1 & 42.2 & 29.1 & 23.1 & 22.0 & 21.9 & 21.3 & 20.4 \\
\hline \multirow{3}{*}{$70 \%$} & 2 & 100.0 & 86.4 & 76.2 & 59.6 & 46.6 & 41.1 & 37.4 & 37.6 & 37.6 \\
\hline & 3 & 100.0 & 82.2 & 68.7 & 49.9 & 38.4 & 33.6 & 30.7 & 31.1 & 31.1 \\
\hline & 5 & 93.6 & 75.2 & 58.3 & 42.1 & 32.6 & 30.4 & 29.2 & 28.0 & 26.6 \\
\hline \multirow{3}{*}{$75 \%$} & 2 & 100.0 & 95.8 & 84.2 & 69.6 & 55.0 & 48.6 & 44.2 & 43.5 & 43.2 \\
\hline & 3 & 100.0 & 88.5 & 79.8 & 58.9 & 46.0 & 40.4 & 39.6 & 38.9 & 38.2 \\
\hline & 5 & 100.0 & 85.5 & 68.2 & 50.1 & 39.3 & 36.5 & 34.6 & 34.5 & 33.1 \\
\hline \multirow{3}{*}{$80 \%$} & 2 & 100.0 & 100.0 & 92.9 & 82.4 & 65.8 & 58.3 & 52.8 & 51.9 & 50.4 \\
\hline & 3 & 100.0 & 94.0 & 86.8 & 70.4 & 55.7 & 49.2 & 47.4 & 45.5 & 44.0 \\
\hline & 5 & 100.0 & 88.2 & 77.9 & 60.3 & 47.9 & 42.8 & 40.9 & 40.5 & 39.2 \\
\hline \multirow{3}{*}{$85 \%$} & 2 & 100.0 & 100.0 & 98.4 & 86.8 & 70.8 & 63.7 & 57.4 & 55.3 & 53.9 \\
\hline & 3 & 100.0 & 100.0 & 91.2 & 75.2 & 61.0 & 52.6 & 48.8 & 47.3 & 44.4 \\
\hline & 5 & 100.0 & 95.5 & 82.5 & 66.8 & 51.0 & 45.7 & 45.4 & 42.5 & 41.1 \\
\hline
\end{tabular}

Fig. 1. Peak rate of runoff flow for reduction in sponge city construction measures. (\%)

\subsection{Source of emission reduction}

Source emission reduction, as the name implies, is to achieve the reduction and discharge of rainwater at the source, which is a drainage technology with very little impact on the environment. Its core technology is that it can operate at the source through a certain technology, and it will not make the surrounding environment change too much before and after the operation. In the encounter of small and medium - sized rainfall, we can use the source emission reduction method, this method can let the rainwater into the flood discharge pipeline through penetration, storage, regulation and cleaning to achieve the control of the runoff at the source. Source emission reduction can absorb rain before infiltration, which reduces the ground runoff and reduces the peak runoff. After finishing the above series of operations, you can further reduce the other runoff discharge by adjustment and storage. Some vegetation can also be planted to slow the runoff, so that the peak runoff can be reduced [5].

\subsection{Penetration measures}

Another way in sponge cities to reduce rain and waterlogging disasters is to build infiltration measures, which can speed up its infiltration speed in the process of rainwater flow. The general penetration measures are the concave green space, rain garden and permeable pavement. These infiltration measures can separate the runoff on the ground in time during the heavy rain, without causing very deep ground water in the city. This 
way of drainage can make people live a better life. These infiltration measures are mainly composed of rainwater inlet, drainage pipes and outlets, so that the design can have a better destination.

\section{The Benefit Analysis of Sponge City Construction}

Sponge city will have very good economic and ecological benefits during its construction, which can not only bring economic development to the city of sponge city construction, but also beautify the environment, the ecological quality can also be improved and slow down the hot island effect of the city. The construction of the sponge city can not only let the rainwater drain away faster, but also can better protect the urban environment. Sponge cities in the actual use process costs significantly less than the original rain drainage system. In order to determine the scale of sponge city should be suitable in the process of implementation, its economic and social benefits.

\subsection{Economic Benefit Analysis}

The economic benefits of building a sponge city have the following points. First it can reduce the cost of rainwater system construction. Sponge city can not only reduce the ground runoff and delay the time of peak rainfall, but also reduce the burden of urban rainwater system drainage to a certain extent. And the cost of building a sponge city is much less than the original rainwater system, so the income can be calculated according to the reduced drainage in a unit area. Second it can no small from using the rain water. The sponge city has a reservoir that can collect a lot of rain water after construction. The rain water can be used in many places after a certain way of treatment. For example, it can be used to make fountains, water in sprinklers, but also to clean vehicles, etc. Such a gift method can not only reduce the use of tap water but also be calculated by such use of wastewater and the price of local tap water. Third it can reduce the cost of grass backfilling. In the process of building a sponge city, the lower concave green space will be selected, so as to reduce the backfill amount of the green space and reduce the cost of backfilling the green space [6].

\subsection{Social Benefit Analysis}

Building a sponge city can not only reduce the ground runoff of the city, but also restore the local environment to a new ecological landscape. Therefore, the social benefits of building a sponge city have the following points. First building a sponge city can not only reduce the risk of urban waterlogging, but also reduce the losses caused by citizens in the floods. Second the construction of sponge city can make the infiltration speed of rainwater get faster and more, and the infiltration of rainwater can well recharge the groundwater. Third the construction of sponge city will put forward very high requirements for the proportion of green space and ponds, and the increase of the proportion of green space and ponds will make the city more suitable for people to live in. Such a good environment will also attract more tourists to travel and promote the local economic development.

\section{Conclusion}

With the continuous improvement of rainwater system, the construction of waterlogging prevention system in sponge city has developed very rapidly. The construction of waterlogging prevention system can make the development of sponge city simpler and fast. So if you want the sponge city to really build up, the improvement of the rainwater system is essential.

\section{Acknowledgments}

Study on landscape evaluation of Pinglian Expressway Based on digital mode (Grant No.2020H0115); Jiangxi Provincial Department of Science and Technology (Grant No.2021B0501; Grant No.2021B0502).

\section{References}

1. Hu, A.B.Ren, X.X(2010)Create a low zone for utilization utilization utilization utilization utilization impact area in Shenzhen. Water supply and drainage in China.20:169-172.

2. Zhao, D.Q.Chen, J.N.Tong, Q.Y, etc. (2008) Construction of SWMM Urban Drainage Pipe Network Model Based on GIS. China water supply discharge.7: 188-19.

3. Liu, D.M.Zhang, C.Li, M.(2016)Reconstruction of RainWater Network Based on Multi - objective Optimization Model. South - to - North Water Diversion Project and Water Conservancy Science and Technology.14: 183-187.

4. Che, W.Zhao, Y.Li,J.Q, etc.(2015)Basic Concept and Comprehensive Objective of the Sponge City Construction Guide. Water supply and drainage in China.8:101-105.

5. Pan, G.Q.Che, W.Li,J.Q, etc.(2008)Urban runoff pollution control volume and its design rainfall. Water supply and drainage in China.22:125-129.

6. Wang, C.J. (2010) Study on Rainwater and Medium Water Utilization in Buildings and Community of Hefei. School of Civil and Water Conservancy Engineering, Hefei University of Technology.8:101105 . 